Sylvain Parent, Aurélien Girard, Laura Pettinaroli, Atlas des chrétiens. Des premières communautés aux défis contemporains

Paris, Éditions Autrement, coll. «Atlas/Monde », 2016, 96 p.

Rodolfo de Roux

CpenEdition

Journals

Édition électronique

URL : http://journals.openedition.org/assr/28346

DOI : $10.4000 /$ assr.28346

ISSN : $1777-5825$

Éditeur

Éditions de l'EHESS

Édition imprimée

Date de publication : 31 décembre 2016

Pagination : 365

ISSN : 0335-5985

Référence électronique

Rodolfo de Roux, «Sylvain Parent, Aurélien Girard, Laura Pettinaroli, Atlas des chrétiens. Des premières communautés aux défis contemporains », Archives de sciences sociales des religions [En ligne], 176 | octobre-décembre 2016, mis en ligne le 20 juillet 2017, consulté le 24 septembre 2020 URL : http://journals.openedition.org/assr/28346 ; DOI : https://doi.org/10.4000/assr.28346

Ce document a été généré automatiquement le 24 septembre 2020.

(c) Archives de sciences sociales des religions 


\section{Sylvain Parent, Aurélien Girard, Laura Pettinaroli, Atlas des chrétiens. Des premières communautés aux défis contemporains}

Paris, Éditions Autrement, coll. « Atlas/Monde », 2016, 96 p.

\section{Rodolfo de Roux}

\section{RÉFÉRENCE}

Sylvain Parent, Aurélien Girard, Laura Pettinaroli, Atlas des chrétiens. Des premières communautés aux défis contemporains, Paris, Éditions Autrement, coll. « Atlas/ Monde », 2016, 96 p.

1 Ce petit ouvrage, par la taille, mais non par son contenu, tient la promesse faite dès son «Introduction» : rendre compte, en moins de cent pages, de la diffusion spatiale des identités chrétiennes sur près de vingt siècles en montrant le déplacement du centre de gravité du christianisme au cours de son histoire. Celui-ci est à présent très largement minoritaire dans la partie orientale du bassin méditerranéen où il est né. Et si, jusqu'au début $d u \mathrm{XVI}^{\mathrm{e}}$ siècle, la quasi-totalité des chrétiens était concentrée en Europe, en 2010 cette dernière ne comptait plus que $25,9 \%$ des 2,2 milliards de fidèles, toutes Églises et confessions chrétiennes confondues. Le dynamisme vient maintenant des Amériques, mais aussi et surtout de l'Afrique subsaharienne, où le nombre des chrétiens a explosé depuis la deuxième moitié $\mathrm{du} \mathrm{xx}^{\mathrm{e}}$ siècle jusqu'à constituer près de $24 \%$ des chrétiens dans le monde à l'heure actuelle.

2 Pour éclairer ces évolutions et recompositions récentes, l'atlas dirigé par Sylvain Parent privilégie une approche historique large plutôt que de se limiter à une 
présentation détaillée du christianisme contemporain. L'autre caractéristique de l'ouvrage est son approche globale de l'implantation du christianisme. La prise en compte de toutes les aires géographiques et confessions permet de mieux dégager des héritages multiples et fait ressortir les conditions de la diversification des Églises chrétiennes au cours des siècles.

3 Afin de répondre à ce choix de globalité et de longue durée, l'ouvrage s'articule autour de cinq parties thématiques. La première partie, «Expansion », part des fondements du christianisme en insistant tout particulièrement sur sa dynamique missionnaire et sur ses étapes clés, exposées en huit thèmes : la naissance du christianisme ; sa diffusion dans l'Empire romain; la christianisation de l'espace urbain, avec l'exemple de Rome ; la conversion de l'Occident au Moyen Âge; les ordres mendiants et l'ouverture du christianisme sur le monde aux $\mathrm{XIII}^{\mathrm{e}}$ et $\mathrm{XIV}^{\mathrm{e}}$ siècles; la conquête spirituelle des Amériques; les missions en Afrique; le christianisme en Asie et dans le Pacifique. Comme pour le reste de l'ouvrage, chaque thème occupe deux pages de texte explicatif, avec cartes et graphiques.

La seconde partie, «Un christianisme pluriel », expose en douze points thématiques la diversité des principales Églises chrétiennes depuis l'Antiquité, et revient sur les scissions multiples qui les ont déchirées - et les déchirent encore. La troisième partie, "Pratiques du christianisme", est constituée des cinq thèmes suivants: le monachisme ; les saints et la sainteté ; les pèlerinages ; le christianisme au féminin ; les Églises et l'enseignement du Moyen Âge aux Temps modernes. La quatrième partie, "Les chrétiens et les autres : cohabitation et conflits », met en avant les rapports des Églises chrétiennes avec les autres religions monothéistes en abordant les thèmes suivants : les communautés chrétiennes en terre d'Islam au Moyen Âge ; Jérusalem à l'époque des croisades; les chrétiens du Moyen-Orient, des Ottomans à nos jours; chrétiens et Juifs en Occident, du Moyen Âge aux Temps modernes; de l'Inquisition à la censure : répression et contrôle dans l'Église catholique. Enfin, la dernière partie traite quelques-uns des défis auxquels les Églises chrétiennes sont confrontées depuis la fin $\mathrm{du} \mathrm{xx}^{\mathrm{e}}$ siècle : la déchristianisation en Europe ; l'Église catholique face à la modernité ; l'expansion du pentecôtisme et du charismatisme; l'œcuménisme et le dialogue interreligieux; les persécutions contemporaines en Europe; les chrétiens dans la diplomatie et l'humanitaire.

5 Grâce à des cartes et des graphiques aux couleurs vives qui agrémentent sa consultation et à des commentaires historiques qui vont à l'essentiel de chaque thème, cet atlas constitue une bonne initiation à la compréhension des dynamiques spatiotemporelles de la diffusion et de l'implantation du christianisme dans toute sa diversité. Dans l'éventualité d'une seconde édition, les corrections suivantes devraient être apportées : les jésuites développèrent le système des " réductions » au Paraguay à partir de 1609, et non de 1605 (p. 22) ; à la page 26, il est écrit que le diocèse de Goa fut créé en 1534, mais la carte de la page 27 indique 1533 - il faudrait choisir entre 1533 (31 janvier), date de la création du diocèse, ou 1534 (3 novembre), date où le pape Paul III a confirmé l'érection du diocèse. Il serait également bienvenu d'inclure des cartes, graphiques et textes expliquant de façon plus détaillée les dynamiques religieuses aux $\mathrm{xx}^{\mathrm{e}}$ et $\mathrm{xxI}^{\mathrm{e}}$ siècles dans les Amériques et dans l'Afrique subsaharienne, où se trouvent actuellement un peu plus de $60 \%$ de la totalité des chrétiens. 